\title{
Exploring Infant and Young Child Feeding Practices in the Royal Borough of Greenwich, London, to Improve Health and Nutrition Outcomes in Children Under 2 Years of Age
}

\section{Beijuka Diana Kenyangi}

Doncaster Metropolitan Bureau Council, Public Health: Children, Young People and Families. Civic Office, Waterdale, Doncaster, DN1 3BU

\section{Regina Susan Keith}

University of Westminster, School of Life Sciences, Food Nutrition and Public Health Division, 115 New Cavendish Street, London. W1W 6XH

\section{Amanda Rodrigues Amorim Adegboye}

University of Greenwich, Faculty of Education and Health, Department of Psychology, Social Work and Counselling. Park Row, SE10 9LS 


\section{Abstract}

Introduction: The UK, like many other countries, is struggling to achieve two of the Global Nutrition Targets, namely increasing exclusive breastfeeding and halting the rise of childhood obesity. Identifying the infant feeding interventions that are having an impact could increase the effectiveness of cash strapped public health services in London. Improving infant feeding practices could also help halt the dangerous rise in childhood obesity.

Study Aim: This study explored the Infant and Young Child Feeding (IYCF) practices and support in place to improve health and nutrition outcomes of children under 2 years of age in the Royal Borough of Greenwich, London

Methodology: The study applied a qualitative methodology, supplemented with data on demographic characteristics of participants, collected via standardised questionnaires prior to the qualitative data collection. Categorical data are presented as absolute (n) and relative frequency (\%). Qualitative data were collected using focus group discussions, semi structured interviews and key informant interviews and analysed using a thematic approach.

Participants: The total sample included 35 participants: four focus groups with fifteen mothers, nine semi structured interviews, six with mothers and three fathers--all with at least one child in the target age group--and 11 key informants.

Findings: Five main themes and twenty-five subthemes emerged from the qualitative data including a high level of awareness on the importance of infant feeding practices. However, only six of the key informants were aware of the borough IYCF Policy. Key informants felt that they personally would benefit from more training and resources, while more support from health workers, family and friends was very important for the other participants. Support services offered at the Children's Centres appeared to be the most effective, in comparison to support at hospital and at home. There was a lack of cohesion among messages given at the different points of care of breastfeeding moms. Respondents reported that the Borough was implementing some aspects of its infant feeding support programmes effectively, especially through the breastfeeding support groups.

Conclusions: Continuous monitoring and evaluation of current programmes and creation of sustainable links between all points of care from antenatal to postnatal period will help the Borough in achieving improved breastfeeding rates. This should improve health and nutrition outcomes for children under 2 years of age in the borough.

Keywords: Infant and Young Child Feeding Practices, Breastfeeding, Infant and Young Child Feeding Support, Infant and Young Child Feeding Interventions, Infant Feeding Policy 


\section{INTRODUCTION}

Nutrition has gained increasing political attention with global advocacy supporting research to highlight its importance on health (Independent Expert Group, 2016; Gillespie, et al., 2013). This increased attention is a response to the fact that every year, almost half of all under 5 deaths are related to undernutrition (Wang, et al., 2014). In 2012, the World Health Assembly - WHA (an annual meeting of health ministers from 193 countries) agreed on a comprehensive plan for implementing targets for maternal, infant and young child nutrition, to improve health and nutrition outcomes (World Health Organisation (WHO), 2012). The UN Secretary General dedicated 2015-2025 as the Decade of Action on Nutrition, to support countries to achieve their nutrition targets; this was adopted by the UN General Assembly, in 2016.

Target 5 of the Decade's Global Nutrition Targets is to "increase the rate of exclusive breastfeeding in the first 6 months up to at least 50\%" (WHO, 2014). Exclusive breastfeeding for six months is a cornerstone of survival for children, and evidence shows that it could prevent 823,000 of the 5.1 million under-fives annual deaths (Bhutta, et al., 2008; Black, et al., 2013; Victora, et al., 2016)

WHO recommends optimal infant and young child feeding practices, defined as: initiation of breastfeeding within the first hour of birth, exclusive breastfeeding (the practice of giving only breast milk, with no other food or water) from birth to 6 months of age, and continued breastfeeding to 2 years or beyond, alongside appropriate complementary food from 6 months until the child can share the family food (WHO, 2019). Despite this recommendation, global rates of breastfeeding remain low, with only $40 \%$ of infants under 6 months of age being exclusively breastfed, and less than $50 \%$ continuing to be breastfed up to 2 years (UNICEF, 2018).

In the United Kingdom (UK), according to the last Infant Feeding Survey (IFS), 2010 (Health and social care information centre, 2012), breastfeeding initiation was high at $81 \%$, with a decline to $78 \%$ after 2 days and to $57 \%$ at 6 weeks. Exclusive breastfeeding was at $69 \%$ at birth, falling to $46 \%$ at 1 week and to $23 \%$ by 6 weeks. By 6 months, the percentage of infants exclusively breastfed remained at around $1 \%$, as in previous years.

These findings indicate a low level of compliance with the UK Department of Health's (DH) recommendations (DH, 2012). Low breastfeeding rates have in turn led to increased artificial feeding, which has been associated with increased risk of childhood obesity, noncommunicable diseases, and infections and reduced cognitive function (Wallby, et al., 2017; Victora, et al., 2016). Improving breastfeeding rates in the UK could reduce the risk of these problems and potentially save the National Health Service (NHS) up to $£ 50$ million a year (UNICEF UK, 2019).

Several factors have been found to influence parents' infant feeding decisions such as: support from family and friends (Mahoney and James, 2000; Brown, et al., 2011), media (Henderson, et al., 2000; Kong and Lee, 2004), knowledge of breastfeeding (Shelton, 1994; Gage, et al., 2012), intention to breastfeed (Blyth, et al., 2004; DiGirolama, 2005; Forster, et al., 2006) and age (Blyth, et al., 2004; Forster, et al., 2006; Bolling, et al., 2006).

Currently the UK guidelines on complementary feeding age is to start at around 6 months, when the infants are developmentally ready (Scientific Advisory Committee on Nutrition (SACN), 2018). The European Food Safety Authority (EFSA) (2009 and 2019), however, recommends introduction of complementary food between 4 and 6 months, creating a potential lack of clarity in how to advise parents. 
Considering the influences on decisions and barriers to breastfeeding, several interventions have demonstrated effective impact in improving breastfeeding rates globally and in the UK. WHO et al. (2014) suggests expansion and institutionalisation of the WHO and UNICEF (1991) Baby Friendly Hospital Initiative (BFI) as a key approach. The initiative is based on ten steps to successful breastfeeding (WHO, 2017), which include having clear policies in place, with training and resources to support the policy implementation, especially to reach the most vulnerable populations. These interventions have been most effectively implemented through peer support programmes, supported by clear information given to mothers antenatally and postnatally (Black et al 2013, 2016). The provision of clear community-based strategies to support breastfeeding, with the integration of breastfeeding promotion and support throughout the maternal and child health continuum, is essential. Staff need to encourage and support practices such as rooming in (the infant sleeping in the same room as the mother), early initiation of breastfeeding (within an hour of birth) and the effective positioning of the child (to prevent pain and cracked nipples). The initiative further supports active implementation of the International Code of Marketing of Breast-Milk Substitutes (World Health Organisation, 1981) and relevant subsequent WHA resolutions, and investment in training and capacity building for breastfeeding protection, promotion and support.

The 2006 Millennium Cohort study, the first known UK-wide evaluation of the BFI, found that mothers who delivered in a Baby Friendly unit were $10 \%$ more likely to start breastfeeding, but concluded that the same mothers were not more likely to continue breastfeeding up to 1-month postpartum (Bartington, et al., 2006). Similarly, in Brazil, high rates of exclusive breastfeeding were realised when hospitals incorporated the BFI into their staff training courses, but this increase was short lived and not sustained, until postnatal home visits were added (Coutinho, et al., 2005). Evidence indicates that breastfeeding support for mothers after discharge from maternity units is essential for improving breastfeeding rates. A comparison between the 2005 and 2010 UK infant feeding surveys shows an increase in breastfeeding initiation rates from 2005 to 2010, which could be a result of increased implementation of the BFI (UNICEF UK, 2019).

\section{Royal Borough of Greenwich, London}

The Royal Borough of Greenwich is located on the banks of the river Thames in Southeast London. The estimated 2017 population was 277,137 with 0-2year olds accounting for about 5\% (Greater London Authority, 2015). In 2014, the Borough reported 26\% of its children living in poverty, compared to 24\% and 20\% in London region and England respectively (Royal Borough of Greenwich, 2019a). Overweight and obesity among children under 5 years of age was at 29\%, higher than in London and England at $19 \%$ and $21 \%$ respectively (Royal Borough of Greenwich, 2016). In response, the Borough increased investments in children's services.

According to Public Health England (2017), the breastfeeding initiation rates in the Borough were about $82 \%$, higher than the national average of about $75 \%$. Data for Greenwich on breastfeeding prevalence at 6-8 weeks in 2017/2018 were not published by Public Health England. This was because the Borough had a large number of infants whose breastfeeding status was unknown, hence it did not pass national data validation criteria (Royal Borough of Greenwich, 2019a). It is known, however, that breastfeeding rates in the Borough are generally lower in teenage mothers and in white British mothers than in others (Royal Borough of Greenwich, 2019a). 
Breastfeeding in the Borough is supported by the Greenwich Breastfeeding Strategy, a partnership of Royal Greenwich, Queen Elizabeth Hospital, Oxleas NHS foundation trust and the University of Greenwich. The strategy aims to improve rates of breastfeeding and wellbeing of all mothers and children (Royal Borough of Greenwich, 2014). A key location for implementing the strategy in the Borough are the Children's Centres. These are establishments, located across the Borough, to increase families' access to various services combined into one nearby location. They provide antenatal advice and information and guidance on infant feeding, among other things (Royal Borough of Greenwich, 2017a). In 2017, the Borough became the first London borough to achieve the UNICEF BFI accreditation (Royal Borough of Greenwich, 2017b). The council public health team believed that this would help them to meet the national breastfeeding initiation target of 85\% (National Health Service, 2014).

Exploring the impact of the Borough's interventions could help improve the health and nutrition outcomes of its children. There is growing concern on the negative impact of austerity measures on household income and local council budget cuts requires more in-depth information to support evidenced, informed decision making and future planning in the Borough.

\section{Aim and objectives of study}

The main aim of the study was to explore the infant and young child feeding (IYCF) practices in the Royal Borough of Greenwich in children under the age of 2, through 3 specific objectives, which were:

1. To identify what evidence exists on the perceived effectiveness of implementation of interventions to improve IYCF practices and related health outcomes

2. To assess the perceived impact of the borough's breastfeeding policy and strategy

3. To feed into policy and practice for improving young child nutrition support services in the borough.

\section{METHODOLOGY}

\section{Research design}

A qualitative approach was applied to address the main study aim and specific objectives. Qualitative research provides an in-depth window on the practices of a community and the reasons why such practices are implemented (Carey 1995). Understanding these influences are essential in supporting the implementation and possible modification of policies.

\section{Study population}

The target population was mothers and fathers of children aged 6 weeks to 23 months, attending either the breastfeeding support group, or the stay and play sessions at the children's centres, and workers involved with IYCF support programmes both at the children's centres and elsewhere in the borough.

\section{Sampling}

The study area was selected using convenience sampling; purposive sampling was used to select the children's centres from which participants were recruited; convenience and snowball sampling approaches were used to select the participants (Brannen, 2010). The lead researcher consulted with the children's centres throughout the sampling process. Planning 
meetings were held with a gatekeeper and key informants from the Borough's Public Health Department. Four children's centres were selected, and consent sought to carry out the research in the centres. The Centres were chosen because all their services target families with children under 5 years of age. On the advice of the children's centre managers, the breastfeeding support group and the stay and play sessions were considered best suited to provide participants to this study. Any parent with at least one child in the target age group, who attended a session on the day when the researcher visited the centres to carry out the research, was eligible to participate.

\section{Ethics}

Ethical approval was obtained from the University of Westminster (ETH1617-0909), and permission to carry out the study was granted by the Royal Borough of Greenwich as well as at each participating children's centre. All participants signed a consent form once they had been given and read the participant information sheet. Participants were advised that they could opt out at any time and informed that they would be offered a summary of the findings. Confidentiality was maintained throughout the study and data was stored securely in a password protected file on the principle investigator's (PI's) computer.

\section{Data collection}

Demographic data were collected from all participants through a confidential simple survey using a standardised questionnaire. These data were used to support the qualitative data. Four focus group discussions (FGD), including fifteen mothers, were facilitated by the PI using a topic guide that had been approved through the gatekeeper. Three of these took place during breastfeeding support group meetings and one during a stay and play session. The FGDs lasted around 45-60 minutes. To avoid disruptions, the FDGs commenced when mothers finished their session with the breastfeeding advocates. Mothers from the stay and play session were taken to a different room. The PI also carried out nine semi structured interviews (SSI) (6 with mothers and 3 with fathers). FGD and SSIs offer a guided and interactive way to get the details of in-depth experiences and reasons behind individuals' beliefs, actions, attitudes and perceptions (Carey 1995). Both these tools encourage informal conversation, allowing participants to use their own words rather than closed yes or no responses, and involves minimal moderator involvement (Powell and Single, 1996). The same question guide was used to implement both FGD and the SSI. Despite the advantages of FGD and SSI, they have been found to elicit more of surface information, and to back this up, the key informant interviews (KII) were important. This tool requires a short time to implement and yet gives good quality data from the key informants, who are often very knowledgeable about the subject in question, thus giving deeper insights (Marshall, 1996). KIIs were conducted by the PI, following informed consent, with eleven key informants (service providers, breastfeeding advocates and IYCF support volunteers). The KIIs lasted 20-30 minutes. Using face to face communication techniques helped the PI to build trust with the participants, supporting participant contributions (Johnson, 2002).

All participants had an opportunity to interact with the PI and each other before the discussions and interviews began. This helped the participants to relax, again increasing trust in the PI.

All discussions and interviews were digitally recorded, following informed consent, to allow the PI to focus on the discussion (Clifford, et al. 2016). The PI noted body language and facial expressions, and at some points during and after each interview or discussion, a summary of key issues raised was shared with the participants to 
increase validity of the study findings (Mays and Pope, 2000). The PI remained at the centre following the conclusion of the FGDs, to encourage elaboration of points by participants, especially if they felt inhibited by the group setting.

\section{Data Analysis}

Every interview and FGD was digitally recorded with participant permission, listened to in full, and then manually transcribed verbatim by PI, to ensure the issues raised by the participants were clear. This also served to increase reflexivity and validity of the research findings (Finlay and Gough, 2008). A thematic approach, as described by Braun and Clarke (2016), was used for analysis. Patterns and variations of meanings were derived from the data collected, identifying emerging themes, which formed the basis of analysis. From the themes, subthemes were identified by the PI and verified, through counting the responses corresponding to themes to ensure appropriate frequency (Miles and Huberman, 1994). The transcripts were coded and themes regularly checked and adjusted for quality. Categorical data were tabulated and presented as absolute (n) and relative frequency (\%).

\section{FINDINGS}

The findings are presented in two parts, participant demographic characteristics, followed by discussion of the themes, supported by related examples of quotes from participants.

\section{Participant Characteristics}

The FGDs and SSIs had 24 participants, 21 mothers and 3 fathers, all with children aged 6 weeks to 23 months. The youngest participant was 26 years old, the oldest 44 years. The oldest mother was 39 years. All participants were resident in the Royal Borough of Greenwich. The KII had 11 participants, all of whom were female, aged 29-69 years, and most of whom were familiar with the Borough's infant feeding policy.

The combined FGD and SSI participant characteristics are shown in Table 1 below.

Table 1. Characteristics of focus group discussion and semi structured interview participants and their Infant and Young Child Feeding practices in the Royal Borough of Greenwich, London

\begin{tabular}{|l|l|}
\hline Characteristics of participants $(\mathrm{n}=24)$ & \\
\hline $\begin{array}{l}\text { Gender } \\
\text { Females } \\
\text { Males }\end{array}$ & $87 \%(21)$ \\
\hline Age (Years) & $13 \%(3)$ \\
$26-30$ & $13 \%(4)$ \\
$31-35$ & $50 \%(12)$ \\
$36-40$ & $33 \%(8)$ \\
$41-45$ & $4 \%(1)$ \\
\hline $\begin{array}{l}\text { Place where child was born } \\
\text { Hospital }\end{array}$ & \\
Other & $92 \%(22)$ \\
\hline $\begin{array}{l}\text { Age of Infant } \\
6 \text { weeks -6 months }\end{array}$ & $8 \%(2)$ \\
\hline >6 months & $52 \%(14)$ \\
\hline $\begin{array}{l}\text { Parity ( } \mathrm{n}=21 \text { moms) } \\
\text { Primipara (First child) }\end{array}$ & $48 \%(10)$ \\
\hline
\end{tabular}




\begin{tabular}{|l|l|}
\hline Multipara (Second or more child) & $38 \%$ (8) \\
\hline Infant feeding Practices ( $\mathrm{n}=24$ FGD and SSI participants) \\
\hline $\begin{array}{l}\text { Intention to Breastfeed } \\
\text { Yes } \\
\text { No }\end{array}$ & $100 \%(24)$ \\
\hline $\begin{array}{l}\text { When decision on feeding method was } \\
\text { made } \\
\text { Before birth of baby }\end{array}$ & - \\
At birth of or after birth of baby & $100 \%(24)$ \\
\hline $\begin{array}{l}\text { Ever Breastfed } \\
\text { Yes } \\
\text { No }\end{array}$ & - \\
\hline $\begin{array}{l}\text { Breastfeeding Initiation } \\
\text { Initiated within first hour } \\
\text { >1 hour }\end{array}$ & $92 \%(22)$ \\
\hline $\begin{array}{l}\text { Age of baby at first visit to children's centre } \\
\text { for IYCF support (n=20 responses) } \\
\text { 0-7 days } \\
\text { 8-14 days } \\
\text { >14 days }\end{array}$ & $8 \%(2)$ \\
\hline $\begin{array}{l}\text { Currently Exclusively Breastfeeding (Babies } \\
\text { 6weeks - 6 months, } n=14)\end{array}$ & $82 \%(9)$ \\
$\begin{array}{l}\text { Yes } \\
\text { No }\end{array}$ & $18 \%(2)$ \\
\hline
\end{tabular}

Six key themes and 25? sub themes emerged from the qualitative data, as listed in Table 2. Each is discussed in more detail below, supported by related quotes from participants.

Table 2. Themes and sub themes emerging from the analysis of qualitative data

\begin{tabular}{|c|c|c|}
\hline Theme & Sub theme & $\begin{array}{l}\text { KII or } \\
\text { FGDs }\end{array}$ \\
\hline $\begin{array}{l}\text { 3.2 Implementation of IYCF } \\
\text { policy }\end{array}$ & $\begin{array}{l}\text { Role of service providers (SPs) } \\
\text { Training of SPs } \\
\text { Collaboration for policy implementation } \\
\text { Advice on breastfeeding and weaning } \\
\text { IYCF } \\
\text { Barriers to policy implementation }\end{array}$ & KIIs \\
\hline $\begin{array}{l}3.3 \text { Influences on type of } \\
\text { feeding method }\end{array}$ & $\begin{array}{l}\text { Friends and family } \\
\text { Media } \\
\text { Knowledge of breastfeeding and available } \\
\text { information }\end{array}$ & $\begin{array}{l}\text { FGDs and } \\
\text { KIIs }\end{array}$ \\
\hline 3.3 Barriers to breastfeeding & $\begin{array}{l}\text { Insufficient support } \\
\text { Aggressive marketing of breast milk } \\
\text { substitutes } \\
\text { Attitudes and socio-cultural issues } \\
\text { Conflicting messages } \\
\text { Friends and family } \\
\text { Pain } \\
\text { Time and effort } \\
\text { Unrealistic expectations } \\
\text { Anatomical challenges (tongue tied) }\end{array}$ & FGD \\
\hline
\end{tabular}




\begin{tabular}{|l|l|l|}
\hline 3.4 IYCF support & $\begin{array}{l}\text { Antenatal support } \\
\text { Postnatal support at the hospital } \\
\text { Postnatal support at home } \\
\text { Postnatal support at the children's centre } \\
\text { Improving support }\end{array}$ & FGDs \\
\hline $\begin{array}{l}\text { 3.5 Perceptions on how to } \\
\text { improve breastfeeding rates in } \\
\text { the Borough }\end{array}$ & $\begin{array}{l}\text { Strategies that can improve breastfeeding } \\
\text { rates, } \\
\text { What has worked to improve breastfeeding } \\
\text { rates? }\end{array}$ & KIIs \\
\hline $\begin{array}{l}\text { 3.6 Infant and Young Child } \\
\text { Feeding sessions at the } \\
\text { children's centres }\end{array}$ & & FGDs \\
\hline
\end{tabular}

\section{Implementation of the Children's Centres Infant Feeding Policy}

\section{Role of service providers, advocates and IYCF support volunteers}

The key informant roles ranged from providing information and signposting, to working directly with the moms and providing practical IYCF support.

"I support moms in breastfeeding and bottle feeding their babies and signpost them to the right information on weaning." [Volunteer]

"In the hospital, I go bed to bed supporting moms who are staying in the hospital after birth. I support them with attachment; maybe help with baby syringe feeding, and cup feeding. In the community, I do breastfeeding support groups and with a midwife team as well where moms and dads come to us with their issues and challenges." [Advocate]

"My role is about the maintenance of the UNICEF baby friendly accreditation within the children's centres in Greenwich.” [Service provider]

\section{Training of service providers, advocates and IYCF support volunteers}

All key informants had been exposed to some training in IYCF, including the UNICEF baby friendly training. However, they all felt that more training was necessary. Experience also came up as an important part of their work.

"Originally, I was a breastfeeding mom so I started as a volunteer. Later we were trained with the UNICEF baby friendly courses. I have a lot of experience and want to have more training." [Advocate]

\section{Collaborations in policy implementation}

There was collaboration between the Borough and children's centre staff and other council departments dealing with young children, especially during the UNICEF-UK Baby Friendly Accreditation process. There was also some collaboration between the key informants working directly with mothers. Participants felt, however, that there was no clear collaboration between the hospital teams and home support teams. 
"For the baby friendly accreditation, we have had close collaboration with children's' centre staff, midwives and health visitors, as well as with different council departments." [Service provider]

\section{Advice on breastfeeding and weaning}

It emerged from the KIIs that advice given was centred around the BFI. The breastfeeding advice was on importance of skin-to-skin contact, responsive feeding, risks of bottle-feeding and milk formula and on breastfeeding techniques. The advice for bottle feeding, given to mixed feeding and bottle feeding mothers, was to make up feeds as needed, to limit the number of feeders and to avoid force feeding, while the message for initiation of complementary feeding was to start at around 6 months and not 4 months because the baby's gut needed to be well developed to handle food.

"When we see a mother for the first time, we make a breastfeeding assessment and encourage them to continue breastfeeding. If they are thinking of formula feeding, we inform them of the disadvantages and how it affects breastmilk supply. If a mother is mixed feeding, we give them a plan, which is usually to express, boost up their milk supply, work on the position and attachment and gradually reduce formula. That's a compromise but it's the best way to keep them breastfeeding." [Advocate]

"With infant feeding we are adhering to the Baby Friendly standards and at the minute we do a bi-weekly email that contains update information and mini posters that children's centres can display at their centres" [Service provider]

\section{Infant and Young Child Feeding}

The participants felt that IYCF was about how to breastfeed, bottle-feed and wean a young child.

"I think it is feeding options in general, bottle feeding, the expressing, giving formula and water for young children." [Experienced mom]

"Perhaps it is about weaning as well, when to introduce foods, the order by which to introduce them and by what age." [26-30 -year-old 1st time mom]

\section{Barriers to implementing the policy}

The key informants who worked directly with the moms felt they were not supported enough, and for all of them, it was difficult to tell if mothers followed the advice given, while several participants felt that having more breastfeeding specialists at each session would improve the service delivery.

"I feel that we could have more support, more staff, more hours of work, because there is so much to do.” [Advocate]

\section{Influences on type of feeding method}

In this theme, we present the findings related to what participants felt were significant influences to infant feeding decisions. 


\section{Friends and Family}

Participants felt that friends and family, and generational practice were big influences. They also felt that the family and support networks around the mother would have great influence on her choices.

"I always thought that I would breastfeed, my mom was always talking to me about how I was breastfed till 2 years old so I always assumed it was the way for me too." [36-40 -year old experienced mother]

"Primarily I would say their history, their timeline, it's what their families have done, their mothers, sisters, friends - what they see around them." [Advocate]

\section{Media}

From the KII, participants felt that the media was very influential in IYCF decision making, especially because of the way bottle-feeding is portrayed in society as normal over breastfeeding.

"I think media as well have a big part to play in the influence of breastfeeding. Definitely. I would like to see royalty breastfeeding their babies in public, and I would like to see in soap operas and films, women breastfeeding. Instead of someone saying here is a bottle, I want to see an actress lifting up her shirt!" [Advocate]

\section{Knowledge of breastfeeding and available information}

Several participants considered knowledge of breastfeeding and information from various sources like books, health professionals and the internet as significant influences.

"We looked at some literature that suggested good benefits to breastfeeding, to see what the current thinking was and what the advice was from experts. We also looked online" [First time Dad].

"When she seemed to be underweight, the advice from the doctors was to go onto formula as part of mixed feeds, and to increase breastfeeding as well." [First time Dad]

\section{Barriers to breastfeeding (Theme three)}

This theme presents findings on participants' experiences and perceptions of barriers to breastfeeding.

\section{Insufficient support}

This was the most common barrier raised and participants felt that there was not enough support available for breastfeeding. One felt that the support was sufficient but the moms were not seeking it.

"What I find quite frustrating is that there is a lot of pressure to breastfeed and yet there is not much support and that's been really hard". [36-40 -year old experienced mother]

"I have not really had much opportunity of support as a feeder myself, focus in the hospital is on the moms and the baby." [First time dad] 
"Unfortunately, many mothers usually come only when there is a problem so we have to work a lot trying to reverse the effect of formula that has been introduced in general, sometimes at the hospital. I usually ask if they have been showed how to hand express or pump breast milk and sometimes the answer is yes, but mainly no." [Advocate]

\section{Marketing of breastmilk substitutes}

The KIIs revealed participants feeling that marketing of breastmilk substitutes was aggressive and clever, thus undermining breastfeeding.

"There is a constant barrage of marketing of formula that it is equal to breastmilk, therefore fine. Once they start mixed feeding, you see breastfeeding prevalence go down and it is difficult to turn it around and even then, it takes time." [Advocate]

"There is still need to cut down more on the marketing of breastmilk substitutes because they are so many. You find a whole isle in the supermarket with lots of fancy stuff for babies, which is not necessary". [Volunteer]

\section{Attitudes and socio-cultural issues}

Society, especially attitudes towards public breastfeeding, was considered a barrier. Religion and culture were also mentioned. Participants also felt that certain attitudes of both moms and health professionals were a barrier.

"We can look at cultural backgrounds and breasts are viewed as a sex object, maybe religion, certain communities believe you should not show your body, although I do not believe that women just show their bodies. I do think it's a lot of people judging them, so they feel judged and they feel judged anyway, whether they are breastfeeding or otherwise so there is this battle between those who are pro-breastfeeding and those who are against breastfeeding." [Advocate]

"You can have access to all the trainings in the world but you cannot change people's in-built attitudes like when you are tired on a night shift there are midwives who will support a mom breastfeeding and others who will just say let's give her a bottle! You can pitch breastfeeding to moms till you are blue in the face but at the end of it all, some just choose not to." [Advocate]

\section{Conflicting messages}

It was felt that sometimes IYCF messages from health professionals were conflicting, and guidelines on when to initiate complementary feeding were still confusing.

"I found it strange that the midwives and the paediatricians had completely different opinions on what should be the amount to feed the baby with midwives saying just a little bit will do and the paediatrician saying she should be having 30ml already on day 2 which was just completely unrealistic!" "I would say I found that between different midwives as well." [31-34-year old 1st time moms]

"Sometimes we tell the mothers one thing and then at the general practitioners, they are told something else. This affects breastfeeding”. [Advocate] 


\section{Family and friends}

Friends and family emerged as a possible hindrance to breastfeeding efforts.

"My mother in law bottle fed and she puts a lot of pressure on me to give a bottle so I think it may be easier if you have family who are pro-breastfeeding." [31-35-year old $1^{\text {st }}$ time mom]

"I was bottle fed. My mom didn't breastfeed me or my sisters and it was often suggested to me when I was struggling, to give a bottle." [31-35 year old $1^{\text {st }}$ time mom]

\section{Pain}

It was felt that pain often contributed to a switch to bottle feeding.

"There were instances during breastfeeding where I nearly gave up just because of the pain; I guess it's not really spoken about.” [29-30 -year old $1^{\text {st }}$ time mom]

"The very first time was okay but it got very painful very quickly so by day 3 I was in a lot of pain!” [36-40-year-old experienced mom]

\section{Poor technique}

Several participants felt unsure about whether they were using the right breastfeeding techniques, and felt that this could be contributing to their struggles with breastfeeding.

" Initially it was very challenging getting the baby to latch properly and there was a lot of pain. Getting the technique right was quite a challenge; I think she (the partner) struggled a bit." [1 $1^{\text {st }}$ time father]

"Finding a position that was comfortable for me and for her, I just couldn't find a way to hold her where I felt comfortable so that was quite frustrating." [31-35-year-old $1^{\text {st }}$ time mom]

\section{Time and effort}

Some participants reported that breastfeeding was too time consuming and needed plenty of effort, with them hardly being able to do anything else.

"I had to breastfeed, express and bottle feed for a number of weeks, which was kind of all I had done for that time so it was a lot of time to spend just on feeding!" [26-30 -year old 1st time mom]

"In the beginning, you feel badly that you can't do anything. I felt that all I could do was feed. I felt like oh I really can't do anything like cook a meal, or go to the toilet. You just feel a bit stupid." [36-40 year old $1^{\text {st }}$ time mom]

\section{Unrealistic expectations}

Most participants felt that the reality of breastfeeding was far from what they expected and felt that there wasn’t enough information to prepare them for this reality. 
"We need to share information about what is normal and managing expectations. Because it's natural, people believe they will give birth and milk will squirt out of them but knowing that it may not happen at all or only happen at day 5 is important.” [Advocate]

"I think one of the biggest things for me specifically is that I found, they say you know if feeding is hurting then you are doing it wrong, that is a bit of a misconception. Expectations should be managed by more education on what that pain actually means." [ $1^{\text {st }}$ time dad]

\section{Anatomical challenges}

The tongue-tie was perceived as a significant barrier, with some moms feeling that it was responsible for their babies failing to latch on.

"We wanted to breastfeed but we really, really struggled through for the first 3 months because he had a tongue tie that never got picked up.” [31-35 -year old $1^{\text {st }}$ time mom]

"We had an undiagnosed tongue-tie with my son. He just cried every single feed and yet he constantly wanted to feed. He was clearly not getting enough milk out so each fed was like a crazy screaming battle." [36-40 year old $1^{\text {st }}$ time mom]

\section{Infant and Young Child Feeding Support in the Borough}

The issue of IYCF support emerged as the fourth theme.

\section{Antenatal support}

Reading material and information from health professionals came up as the main forms of antenatal support available.

"A lot of support was pre-birth material that we received, talking to midwives and reading up.” [1 $1^{\text {st }}$ time dad]

"We went to a National Childbirth Trust (NCT) class before she was born and got knowledge about what feeding involves." [1 $1^{\text {st }}$ time dad]

\section{Postnatal support at the hospital}

Participants felt that support at the hospital was lacking. This feeling was mostly projected by first time moms who generally felt that they needed extra help.

"Mine was quite a mess, I found some of the midwives would just come and shove him on to me without showing me what to do especially at night which wasn't brilliant." [31-35 -year $1^{\text {st }}$ time mom]

"I wasn't very happy with the support either when I was at the hospital. Because I was a new mom, I didn't know when the milk was coming and they said not to worry, it will come, your baby will be fine. He wanted to feed and I was like this can't be right, it's not normal and I was right, it wasn't because after 5 days we found out he was losing so much weight and he may be dehydrated. We freaked out because we could have given him formula; I was quite disappointed with that." [36-40 year old $1^{\text {st }}$ time mom] 
"First time around I felt completely lost, baby was sleeping all the time, I was struggling to wake her up and the midwives always said they would come by when she woke. I trusted them and it was over 24 hours and the baby had not had a feed. I was then told to express with my hand and my hubby catches with a syringe and I was like how? It is impossible, first time mom, out of caesarean section you are in pain, you don't know what you are doing, you are crying, baby is sleeping, nobody comes!" [36-40-year-old experienced mom]

\section{Postnatal support at home}

Some participants felt that support from health professionals at home was lacking, while others felt that it was helpful. Participants reported that, rather than give IYCF support, health visitors referred them to the breastfeeding group at the children's centres. Some felt that the midwife and health visitor visits were poorly timed (day 1 and 5 for the midwife and day 11 for the health visitor), and they missed the most vulnerable times. Support from family/ friends was an important part of postnatal support at home.

"I did have a midwife coming home so they supported me with the latching and they did tell me to stop bottle feeding because it is better for babies to breastfeed more so they were really supportive." [26-30 -year $1^{\text {st }}$ time mom]

"When the health visitor came home, I was in agony and she said it is fine, this is normal and they left. I think it is ridiculous that you have a visit on day 1 and 5 and yet the blues normally hit on day 3 and that's when you need the support and there is none." [31-35 yearold $1^{\text {st }}$ time mom]

"The health visitor came to my home a couple of times and told me about the children's centre and gave me appointments there." [31-35 year old $1^{\text {st }}$ time mom]

\section{Postnatal support at the children's centres}

This was a generally positive experience, especially in the breastfeeding groups. Moms here felt that they had been helped with various feeding problems, ranging from technique, to diagnosis of tongue ties and referrals for management, and above all, these groups improved confidence in themselves.

"Since I started coming here, his weight is picking up again because I got some advice here regarding positioning of the baby for proper latching. I was also given a referral for the tongue tie" [31-35 -year-old experienced mom]

"they will sit with you for quite a long time to help you and you may speak to other moms who might have ideas that you haven't tried, it reassures you that other people have the same issues that you do" [26-30-year-old 1st time mom]

"I did come here once and I was thinking of starting him on bottle feed so I spoke to a health visitor who said to give him during the day and not at night as that will affect the breastmilk production. So I said okay, I wanted to do it at night so I could sleep a bit longer so that's no good and I gave it up." [26-30 year old $1^{\text {st }}$ time mom]

"I had support from my friends and family and I went to stay with my mom for a bit after I left the hospital." [36-40 year old $1^{\text {st }}$ time mom] 


\section{Improving support}

All participants had some ideas on how support could be improved. One mom felt that it was too much pressure on the midwives to deal with feeding and didn't feel that it was their job. Another pointed out the importance of promoting breastmilk alongside breastfeeding. The key informants felt that more antenatal support would be very helpful.

"I so wonder about whether it is really the job of the midwives to teach us about breastfeeding. Their job is to deliver babies. Surely, the NHS should employ more breastfeeding specialists; every woman that gives birth should have a visit in the first 2 or 3 days, not a health visitor but a breastfeeding specialist. That would have probably solved all my problems." [31-35-year-old $1^{\text {st }}$ time mom]

"I think it would help to promote breast milk as much as breastfeeding, what you want is to give the milk. Through which the child gets it is something else." [35-40-year-old experienced mom]

"I do think it is key that we need more antenatal moms to come to our breastfeeding groups. When the baby is born, it's just overwhelming so you need to be fully prepared." [Service provider]

\section{Perceptions on how to improve breastfeeding rates in the}

\section{Borough}

This theme presents the results of what key informants felt would help to improve breastfeeding rates and what they feel has made a positive impact on breastfeeding rates in the Borough.

\section{Strategies that can improve breastfeeding rates}

Achieving complete cohesion at all points of care, making breastfeeding the norm, increased antenatal and hospital level support, more breastfeeding groups, suppression of bottles and their images and shifting the message from breastfeeding benefits to bottle feeding risks were some of the strategies mentioned.

"I think early support in the hospital makes a very big difference. It needs to be strengthened." [Advocate]

"I would like to see bottles disappearing from pictures on cards and from children's toys. I think we are a little bit too soft as far as breastfeeding is concerned, not wanting to upset people. We need to talk less about the advantages of breastfeeding and more about the dangers of bottle feeding.” [Advocate]

"For me it's about having that whole systems approach to anything. It's not enough to have one set of buildings or staffing area trained and equipped to deliver information, it needs to be at every access point that a mom or mom to be has access to and ensuring that the breastfeeding messages are accurate and easy to interpret.” [Service provider] 
The key informants felt that the UNICEF UK BFI had made a positive impact, due to its strict implementation. They also felt that the breastfeeding groups had increased confidence in moms. Both programmes were credited as having taken steps to normalise breastfeeding.

"The UNICEF baby friendly initiative has worked and the key is about normalising breastfeeding as the preferred feeding option. It also gives staff a real focus. Particularly what I think is working in Greenwich is the fact that we do have the same accreditation at every point where a mother will be, which means they will be getting the same messages and the same offer and level of support." [Service provider]

"I would say having the breastfeeding groups at the children's centres has worked but it needs to be more at the hospital because by the time they come here, it's already more than 48 hours and that may be late." [Advocate]

\section{Infant and Young Child Feeding Sessions at the Children's}

\section{Centres}

Regarding the IYCF sessions at the children's centres, participants found them and courses helpful and/or appropriate. Moms felt more confident to breastfeed after attending a breastfeeding group and liked that it was a drop-in, casual session. They felt satisfied with the courses they had attended on introducing solids and that a positive contribution had been made to their IYCF practices.

"It really helped me with confidence, I was given different options to try and these this session made me realise that the problems I was having, everyone else had." [31-35 yearold1st time mother] "Being a drop-in is quite nice as it gives you leeway in terms of time." [31-35-year-old $1^{\text {st }}$ time mom]

"I like that it's quite casual here, it is drop-in so you don't have to make an appointment." [35-40-year-old experienced mom]

\section{DISCUSSION}

Optimal IYCF practices (World Health Organisation, 2018) contribute to improved health and nutrition outcomes (Bhutta, 2008; Victora, 2016). The Borough's investments in children's services were perceived as a step in the right direction, with a breastfeeding friendly Infant Feeding Policy and the IYCF support programmes; the UNICEF UK BFI and Breastfeeding support groups, were felt to have the most impact; this is in line with previous research (Bartington, et al., 2006).

For any policy to be effective, however, its implementers must be aware of it. As only six KII were aware of the policy, more work needs to be investing in training and staff support and resources. Those who were not aware of it perceived a training gap, which supports their feelings that more training is necessary in IYCF, especially for key workers. This need for training is also supported by the findings, that conflicting messages from health workers on IYCF practices is a barrier to breastfeeding. This is in line with studies showing that health professionals, to whom the care of these mothers and families is entrusted, are often the source of advice that undermines breastfeeding, either due to insufficient knowledge, personal beliefs or even, influence of companies that promote breast milk substitutes (Martines, et al., 1989; Renfrew, et al., 2012). 
Mothers and fathers in the study showed a high level of awareness of the importance of IYCF practices but were not probed on which practices they considered optimal as defined in WHO, 2017. However, all mothers had the intention to breastfeed, which, according to Blyth, et al. (2004), Di Girolamo, et al. (2005) and Forster, et al. (2006), was among the strongest predictors of initiation and duration of breastfeeding. This awareness and intention did not however, translate into adherence to the Department of Health breastfeeding recommendation (DH, 2012), as not all mothers in the study were still breastfeeding or exclusively breastfeeding by the time of the study. This demonstrates that the challenges are how to convert intention into adherence to the advised optimal infant feeding practices, particularly exclusive breastfeeding. Addressing the barriers identified here could help raise the level of exclusive breastfeeding in line with national and WHO guidelines. Our findings support earlier research that peer support postnatally was the most impactful intervention, but that negative pressure from family and friends and media can influence IYCF practices, especially early introduction of bottle-feeding. These findings are in line with what Mahoney and James (2000) found, that decisions of mothers stemmed from the suggestions of others, mostly family and friends. Shelton (1994) and Gage, et al. (2012) also indicate that knowledge of breastfeeding was important in regards to decision making. There was a high level of knowledge on the importance of breastfeeding. 100\% of respondents reporting starting to exclusively breastfeed; however almost half of these had stopped by six weeks. Further research is needed on a larger sample of the target group to identify causal factors for this. More research would also be helpful to identify the specific media messages that need to be addressed.

IYCF services need to identify and create enabling environments to address these barriers. A study done in a low social economic community of South Australia found that IYCF support, maternal discomfort and breastfeeding in public were major barriers to breastfeeding (McIntyre, et al., 2001 while $\mathrm{Li}$, et al. (2008) reported as a negative, the aspect of women having to give up their regular lifestyles to breastfeed successfully. Insufficient support as well as family and community pressure related to premature introduction of other foods and liquids to the infant were also identified as important barriers to breastfeeding (Piwoz and Huffman, 2015; Gage, et al., 2012). Even though pain is mentioned as a barrier to breastfeeding, Di Girolamo, et al. (2005) and Hector, et al. (2005) suggest that physical pain associated with breastfeeding will likely only affect short-term and not the long-term breastfeeding duration.

As in Manipon (2016) and Hill and Ruggiero (2017), tongue tied infants was another barrier reported in this study. More information and support to address this minor developmental barrier should be introduced into training and management systems in the Borough.

Another major barrier mentioned was the marketing of breastmilk substitutes. The importance of marketing is elevated by the way it is aimed at influencing attitudes towards milk formula and presenting it as equal to, or a better alternative to, breastmilk and making it out to be a lifestyle choice rather than a decision of substantial economic and health consequence (Piwoz and Huffman, 2015). Breast milk substitute companies’ marketing strategies are having perceived impact, as many mothers believed that adding bottle feeds would not negatively affect the infant or the breastfeeding process? More research could be carried out to explore this in more detail.

Regarding support in the Borough, this study revealed that more antenatal support and earlier postnatal support was needed. Unsatisfactory postnatal support from health care professionals, both at the hospital and at home was identified as a barrier to exclusive breastfeeding to six months. The issues of unclear or mixed messages given by health 
workers and the media was raised repeatedly. All 13 first time mothers were particularly vulnerable to the lack of support and mixed messages. At the children's centres, however, the programmes were highly appreciated, showing that the involvement of Children's Centres in IYCF support could improve IYCF practices and potentially improve health and nutrition outcomes of children under age 2. Midwives and health visitors are part of the programmes offered at Children's Centres, running appointments for new moms and supporting the breastfeeding advocates. Extending these services in the hospital and at home, could improve postnatal support for more effective IYCF practices.

It is difficult to tell whether implementation of the UNICEF Baby Friendly Accreditation and the Breastfeeding groups at these children's centres has been effective, as there is currently no specific data to refer to, but in relation to the findings on effective implementation of IYCF programmes.

The Borough meets some of the indicators of effective implementation. There is a policy that favours breastfeeding (Bhandari, et al., 2008), the programmes give families' access to qualified professionals and breastfeeding specialists, with clearly defined roles (Chapman, et al., 2004; Guise, et al., 2003; Hannula, et al., 2008; Bhandari, et al., 2008; World Health Organisation and UNICEF, 2003) and at the Children's centres mothers are given one on one support. Thus individual needs are often met, and the message on breastfeeding and weaning is in line with the WHO and UNICEF (2003) guidelines. In addition to these, every children's centre adheres to the International Code of Marketing of Breast Milk Substitutes (World Health Organisation, 1981).

The findings do suggest that the Borough's increased support for IYCF is having an impact. The positive impact from the breastfeeding groups, which incorporate peer support, is the second most effective interventions.

\section{Limitations}

The limitations of the study include the fact that there was only a small number of participants; however, saturation of data did occur for most responses. More extensive analysis of women in their own homes could help identify more barriers. Most participants were using the services. However, finding out why mothers do not use the services would enrich these research findings. The selection of the location through convenience sampling has been considered unpredictable, due to its vulnerability to hidden biases (Leiner, 2014). However, the location was the most suited to the study question and referral to them by policy makers in the Borough was an important consideration. Financial and time constraints meant that homogenous focus groups were only achieved for gender, but not for age group and parity. More homogenous groups could have given more meaningful responses, especially on influences and barriers to breastfeeding. More continuous monitoring of qualitative and quantitative data would be useful in planning; but even with its small sample size, this research can feed into planning reviews (Guest, et al. 2006). The usefulness of this study is seen in collaboration with the Royal Borough of Greenwich, who have since included it among the resources guiding the assessment of the breastfeeding groups. It will feed into re-assessment for maintenance of the UNICEF baby friendly accreditation status.

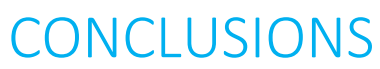

This research explored IYCF practices in the Royal Borough of Greenwich, to contribute to achievement of the long-term goal of improving health and nutrition outcomes of children located there under 2 years of age. The findings identify that mothers using the peer support and child centres believed that these were helpful in supporting them to effectively feed their 
infants. However, more training and resources for health workers could improve support, especially at the hospital and home levels. More research is needed to explore issues of women who are not using the services at present. The positive finding that all women included in the study had started breastfeeding suggests that knowledge around the importance of breastfeeding is reaching families.

Ensuring that the IYCF policy is well known and understood by its implementers could positively contribute to the success of the borough nutrition programmes and support the achievement of the national IYCF target. At the time of this study, the Royal Borough of Greenwich was already a UNICEF UK BFI accredited borough. Significant gaps identified included a lack of data to track the impact of the interventions in the borough and the feeding mothers and families' voices into policy and planning cycles.

Involving the entire set of people that a mother will encounter, on her infant feeding journey is essential. Bridging the gap between points of care from antenatal all the way through to postnatal care, strengthening collaborations between hospitals, GPs, community midwives, health visiting teams and Children's Centres is another strategy that may improve breastfeeding rates in the Borough. It is critical that at all points of care, families consistently receive the same key messages as promoted by the UNICEF UK BFI.

Finally, increasing the number and capacity of skilled breastfeeding support teams and setting up more breastfeeding groups could help the Borough to maintain their accreditation and improve breastfeeding rates.

\section{REFERENCES}

Bartington S, Griffiths L J, Tate, A R, et al. 2006. Are breastfeeding rates higher among mothers delivering in baby friendly accredited maternity units in the UK? International Journal of Epidemiology 35:1178-1186. https://doi.org/10.1093/ije/dyl155

Berry J, Griffiths M, Westcott C. 2012. A double-blind, randomized, controlled trial of tongue-tie division and its immediate effect on breastfeeding. Breastfeeding Medicine 7:189193. https://doi.org/10.1089/bfm.2011.0030

Bhandari N, Kabir A K M, Salam M A. 2008. Mainstreaming nutrition into maternal and child health programmes: scaling up of exclusive breastfeeding. Maternal \& Child Nutrition 4:5-23. https://doi.org/10.1111/j.1740-8709.2007.00126.x

Bhutta Z A, Ahmed T, Black R E, et al. 2008. What works? Interventions for maternal and child undernutrition and survival. The Lancet 371:417-440. doi.org/10.1016/S0140-6736 (07)61693-6

Black R E, Victora C G, Walker S P, et al. 2013. Maternal and child undernutrition and overweight in low-income and middle-income countries. The Lancet 382:427-451. https://doi.org/10.1016/S0140-6736(13)60937-X

Blyth R J, Creedy D K, Dennis C L, et al. 2004. Breastfeeding duration in an Australian population: the influence of modifiable antenatal factors. Journal of Human Lactation 20:3038. doi/abs/10.1177/0890334403261109 
Bolling K, Grant C, Hamlyn B, et al. 2006. The Infant Feeding Survey 2005: A survey conducted on behalf of the Information Centre for Health and Social Care and the UK health Department by BMRB Social Research.

http://content.digital.nhs.uk/catalogue/PUB00619/infa-feed-serv-2005-chap1.pdf

Brannen J. In: Baker SE, Edwards R. 2010. How Many Qualitative Interviews is Enough? Expert Voices and Early Career Reflections on Sampling and Cases in Qualitative Research. National Centre for Research Methods Review Paper, pp16-17.

Braun, V, \& Clarke, V. (2012). Thematic analysis. In H. Cooper, P. M. Camic, D. L. Long, A. T. Panter, D. Rindskopf, \& K. J. Sher (Eds.), APA handbook of research methods in psychology, Vol. 2. Research designs: Quantitative, qualitative, neuropsychological, and biological (pp. 57-71). Washington, DC, US: American Psychological Association. http://dx.doi.org/10.1037/13620-004

Brown A, Raynor P, Lee M. 2011. Healthcare professionals' and mothers' perceptions of factors that influence decisions to breastfeed or formula feed infants: a comparative study. Journal of Advanced Nursing 67:1993-2003. https://doi.org/10.1111/j.1365-2648.2011.05647.x

Carey M A. 1995. Comment: Concerns in the Analysis of Focus Group Data. Qualitative Health Research 5:487-495. https://doi.org/10.1177/104973239500500409

Chapman D J, Damio G, Young S, et al. 2004. Effectiveness of breastfeeding peer counselling in a low-income, predominantly Latina population: a randomized controlled trial. Archives of Pediatrics \& Adolescent Medicine 158:897-902.

https://doi.org/10.1001/archpedi.158.9.897

Clarke V, Braun V. 2016. Thematic Analysis. The Journal of Positive Psychology, 12:297298. doi.org/10.1080/17439760.2016.1262613

Clifford N, Cope M, Gillespie T. 2016. Key Methods in Geography. London: Sage

Coutinho S B, de Lira P I C, de Carvalho Lima M, et al. 2005. Comparison of the effect of two systems for the promotion of exclusive breastfeeding. The Lancet 366:1094-1100. https://doi.org/10.1016/S0140-6736(05)67421-1

Di Girolamo A, Thompson N, Martorell R, et al. 2005. Intention or experience? Predictors of continued breastfeeding. Health Education \& Behavior 32:208-226.

doi.org/10.1177/1090198104271971

European Food Safety Authority. 2009. Scientific Opinion on the appropriate age for introduction of complementary feeding of infants. EFSA Journal 7:1423-1461. www.efsa.europa.eu

European Food Safety Authority. 2019. Public consultation: appropriate age for introduction of complementary feeding of infants. https://www.efsa.europa.eu/en/press/news/190417 
Finlay L, Gough B. 2008. Reflexivity: A Practical Guide for Researchers in Health and Social Sciences. Hoboken, NJ, USA: John Wiley and Sons. http://dx.doi.org/10.1002/9780470776094

Forster D A, McLachlan H L, Lumley J. 2006. Factors associated with breastfeeding at six months postpartum in a group of Australian women. International Breastfeeding Journal 1:18 http://internationalbreastfeedingjournal.biomedcentral.com

Gage H, Williams P, Von Rosen-Von Hoewel J, et al. 2012. Influences on infant feeding decisions of first-time mothers in five European countries. European Journal of Clinical Nutrition 66:914. https://doi.org/10.1038/ejcn.2012.56

Gillespie S, Haddad L, Mannar V, et al. 2013. The politics of reducing malnutrition: building commitment and accelerating progress. The Lancet 382:552-569.

https://doi.org/10.1016/S0140-6736(13)60842-9

Greater London Authority. 2015. Population projections - Interim 2015 based BPO projections. https://data.london.gov.uk

Guest G, Bunce A, Johnson L. 2006. How many inter-views are enough? An experiment with data Saturation and variability. Field Methods 18, 59-82. doi:10.1177/1525822x0527990

Guise J M, Palda V, Westhoff C, et al. 2003. The effectiveness of primary care-based interventions to promote breastfeeding: systematic evidence review and meta-analysis for the US Preventive Services Task Force. The Annals of Family Medicine 1:70-78.

https://www.ncbi.nlm.nih.gov/pmc/articles/PMC1466575/

Hannula L, Kaunonen M, Tarkka M T. 2008. A systematic review of professional support interventions for breastfeeding. Journal of Clinical Nursing 17:1132-1143.

https://doi.org/10.1111/j.1365-2702.2007.02239.x

Hector D, King L. 2005. Interventions to encourage and support breastfeeding. New South Wales Public Health Bulletin 16:56-61. http://www.publish.csiro.au/NB/NB05014

Henderson L, Kitzinger J, Green J. 2000. Representing infant feeding: content analysis of British media portrayals of bottle feeding and breast feeding. British Medical Journal 321:1196-1198. http://dx.doi.org/10.1136/bmj.321.7270.1196

Hill R, Ruggiero K. 2017. Infantile Reflux: The Unsuspected Culprit. The Journal for Nurse Practitioners 13:e99. https://doi.org/10.1016/j.nurpra.2016.10.009

Independent Expert Group. 2016. The Global Nutrition Report: From Promise to Impact, Ending Malnutrition by 2030. A peer reviewed publication. http://ebrary.ifpri.org/utils/getfile/collection/p15738coll2/id/130354/filename/130565.pdf

Johnson J M. 2002. Handbook of Interview Research: Context and Method. Thousand Oaks, CA, USA: Sage.

https://www.google.co.uk/search?tbo=p\&tbm=bks\&q=bibliogroup:\%22Online+access:+Sage + Sage + Research+Methods + Online $\% 22 \&$ source $=$ gbs_metadata_r\&cad $=9$ 
Kong S K, Lee D T. 2004. Factors influencing decision to Breastfeed. Journal of Advanced Nursing 46:369-379. https://doi.org/10.1111/j.1365-2648.2004.03003.x

Leiner D J. 2014. Convenience samples from online respondent pools: A case study of the SoSci Panel. International Journal of Internet Science 20(5):1-18. https://www.researchgate.net/profile/Dominik_Leiner/publication

Li R, Fein S B, Chen J, et.al. 2008. Why mothers stop breastfeeding: mothers' self-reported reasons for stopping during the first year. Pediatrics 122:S69-S76. http://pediatrics.aappublications.org/content/pediatrics/122/Supplement_2/S69.full.pdf

Mahoney M C, James D M. 2000. Predictors of anticipated breastfeeding in an urban, lowincome setting. Journal of Family Practice 49:529-529.

Manipon C. 2016. Ankyloglossia and the breastfeeding infant: Assessment and intervention. Advances in Neonatal Care 16:108-113. https://doi.org/10.1097/ANC.0000000000000252

Martinés J C, Ashworth A, Kirkwood B. 1989. Breast-feeding among the urban poor in southern Brazil: reasons for termination in the first 6 months of life. Bulletin of the World Health Organization 67:151. https://apps.who.int/iris/handle/10665/264656

Marshall M N. 1996. Sampling for qualitative research. Family Practice 13:522-526. https://doi.org/10.1093/fampra/13.6.522

Mays N, Pope C. 2000. Assessing Quality in Qualitative Research. British Medical Journal 320:50. https://doi.org/10.1136/bmj.320.7226.50

McIntyre E, Hiller J E, Turnbull D. 2001. Attitudes towards infant feeding among adults in a low socioeconomic community: what social support is there for breastfeeding? Breastfeeding Review 9:13-24

$\leq$ https://search.informit.com.au/documentSummary;dn=441719884451044;res=IELHEA > IS SN: 0729-2759.

Miles M B, Huberman A M. 1994. Qualitative Data Analysis: An Expanded Sourcebook. London: SAGE.

National Health Service. 2014. NHS England Statistical Release. Breastfeeding Initiation and Breastfeeding Prevalence 6-8 weeks. http://www.england.nhs.uk/statistics/wpcontent/uploads/sites/2/2014/03/Breastfeeding-1314-Revised-Data.pdf

Piwoz E G, Huffman S L. 2015. The impact of marketing of breast-milk substitutes on WHOrecommended breastfeeding practices. Food and Nutrition Bulletin 36:373-386. doi.org/10.1177/0379572115602174

Powell R A, Single H M. 1996. Focus Groups. International Journal for Quality in Health Care 8:499-504. https://doi.org/10.1093/intqhc/8.5.499

Public Health England. 2014. Child Health Profile: Greenwich. http://www.gov.uk 
Public Health England. 2017. Official Statistics. Breastfeeding prevalence at 6-8 weeks after birth. 2016/17 Quarter 4. Statistical Commentary, July 2017 release.

https://www.gov.uk/government/statistics/breastfeeding-at-6-to-8-weeks-after-birth-2016-to2017-quarterly-data

Quigley M A, Hockley C, Davidson L L. 2007. Agreement between hospital records and maternal recall of mode of delivery: evidence from 12391 deliveries in the UK Millennium Cohort Study. BJOG: An International Journal of Obstetrics \& Gynaecology 114:195-200. https://doi.org/10.1111/j.1471-0528.2006.01203.x

Renfrew M J, McCormick F M, Wade A, et.al. 2012. Support for healthy breastfeeding mothers with healthy term babies. Cochrane Database Syst Rev, 5. https://doi.org/10.1002/14651858.CD001141.pub4

Royal Borough of Greenwich. 2016. Profile of Children and Young Children. www.royalgreenwich.gov.uk

Royal Borough of Greenwich. 2014. Greenwich Breastfeeding Policy Statement. Guidance and Checklist for Managers. Available from http://greenwichbreastfeeding.com

Royal Borough of Greenwich. 2017a. Royal Borough of Greenwich Children's Centres. http://www.royalgreenwich.gov.uk/info/200076/preschools/249/services_available_at_childrens_centres

Royal Borough of Greenwich. 2017b. Royal Borough of Greenwich Children's Centres Achieve UNICEF Baby Friendly Award.

http://www.royalgreenwich.gov.uk/press/article/940/royal_borough_of_greenwich_childrens _centres_achieve_unicef_baby_friendly_award

Scientific Advisory Committee on Nutrition. 2018. Report on feeding in the first year of life. https://www.gov.uk/government/publications/sacn-report-on-feeding-in-the-first-year-of-life

UNICEF-UK. 2019. The Baby Friendly Initiative. https://www.unicef.org.uk/babyfriendly/ UNICEF-UK. 2001. Implementing the Baby Friendly best practice standards. London: UK Committee for UNICEF.

UNICEF. 2018. UNICEF global databases: Infant and Young Child Feeding. https://data.unicef.org/topic/nutrition/infant-and-young-child-feeding/

Victora CG, Requejo J H, Barros A J, et al. 2016. Countdown to 2015: a decade of tracking progress for maternal, newborn, and child survival. The Lancet 387:2049-2059.

https://doi.org/10.1016/S0140-6736(15)00519-X

Wallby T, Lagerberg D, Magnusson M. 2017. Relationship between breastfeeding and early childhood obesity: Results of a prospective longitudinal study from birth to 4 years.

Breastfeeding Medicine 12:48-53. https://doi.org/10.1089/bfm.2016.0124

Wang H, Liddell C A, Coates M M, et al. 2014.Global, regional, and national levels of neonatal, infant, and under-5 mortality during 1990-2013: a systematic analysis for the 
Global Burden of Disease Study 2013. The Lancet 384:957-979. https://doi.org/10.1016/S0140-6736(14)60497-9

World Health Organisation. 2019. Breastfeeding. https://www.who.int/nutrition/topics/exclusive_breastfeeding/en/

World Health Organisation. 2017. Protecting, promoting and supporting breastfeeding: the special role of maternity services, a joint WHO/UNICEF statement. https://www.who.int/nutrition/publications/guidelines/breastfeeding-facilities-maternitynewborn/en/

World Health Organization. 1981. International code of marketing of breast-milk substitutes.

World Health Organisation and United Nations Children's Fund. 1992. The Baby Friendly Hospital Initiative. http://www.who.int/nutrition/topics/bfhi/en/

World Health Organisation. 2012. 65th World Health Assembly. http://www.who.int/mediacentre/events/2012/wha65/en/

World Health Organisation. 2014. Comprehensive implementation plan on maternal, infant and young child nutrition. http://www.who.int/nutrition/publications/CIP_document/en/

World Health Organization and United Nations Children's Fund. 2003. Global strategy for infant and young child feeding. World Health Organization.

World Health Organisation. (2007). Indicators for Assessing Infant and Young Child Feeding Practices. http://www.who.int/nutrition/publications/iycf_indicators_for_peer_review.pdf 